\title{
Molecular Cloning of cDNA for the Human Interleukin-2 Receptor *
}

\author{
W. C. Greene, J. M. Depper, G. R. Crabtree, S. Rudikoff, J. Pumphrey, R. J. Robb, \\ M. Krönke, P.Svetlik, N. J.Peffer, T. A. Waldmann, and W. J. Leonard
}

\section{A. Introduction}

Interleukin-2 (IL-2 or T cell growth factor) is a 14,500 daltons glycoprotein critically involved in the development of a normal human immune response [1,2]. Recently, cDNA for this lymphokine has been isolated and expressed in both prokaryotic and eukaryotic cells [3-5]. Further, the human IL-2 gene has been cloned, sequenced [6], and localized to chromosome 4. As with other polypeptide hormones, IL-2 exerts its biologic effects through binding to specific high affinity membrane receptors [7]. However, neither IL-2 nor IL-2 receptors are produced by resting $T$ cells $[7,8]$. Following exposure to antigen, $T$ cells binding antigen enter a program of cellular activation leading to de novo synthesis and secretion of IL-2 and expression of IL-2 receptors. The interaction of IL-2 with its cellular receptor then triggers cellular proliferation, resulting in the growth and development of helper, suppressor, and cytotoxic T cells. Thus, induction of IL-2 receptor expression is a principal mechanism by which the specificity and magnitude of the human immune response is regulated. While IL-2 receptors are not present in most human leukemic $\mathrm{T}$ cell lines, these receptors are uniformly expressed in large numbers in adult $\mathrm{T}$ cell

* The Metabolism Branch, the Laboratory of Pathology, and the Laboratory of Genetics, National Cancer Institute, National Institutes of Health, Bethesda, MD and E. I. duPont de Nemours and Co., Glenolden, PA leukemia (ATL) cells infected with human T cell leukemia/lymphoma virus-1 (HTLV1) [9]. Though unproven, it is possible that these receptors are involved in the malignant growth of these leukemic cells.

We have previously demonstrated that monoclonal anti-Tac antibody, prepared by Uchiyama, Broder and Waldmann [10], recognizes the human IL-2 receptor [11-13]. We have characterized the IL-2 receptor on normal activated $\mathrm{T}$ cells as a densely glycosylated, sulfated, and phosphorylated structure containing intrachain disulfide bonds with an apparent $M_{\mathrm{r}}=55000$ [12]. These receptors are composed of a peptide precursor (apparent $M_{\mathrm{r}}=33000$ ) which is cotranslationally processed by $N$-linked glycosylation to two intermediate forms (apparent $M_{\mathrm{r}}=35000$ and 37000 ). Following export to the Golgi apparatus, these intermediate precursors undergo further posttranslational processing, involving the addition of $O$-linked carbohydrate, sialic acid, sulfate, and phosphate. We now describe the molecular cloning, sequencing, and expression of cDNA corresponding to the human IL-2 receptor isolated from HTLV-1-transformed HUT 102B2 cells.

\section{B. Materials and Methods}

HTLV-1-infected HUT 102B2 cells were used as a source of $\mathrm{IL}-2$ receptor protein and RNA. mRNA was prepared from these cells using guanidine isothiocyanate and isopyknic centrifugation in cesium chloride followed by selection of poly $\left(\mathrm{A}^{+}\right)$mRNA 
with oligo(dT)-cellulose. Using approximately $5 \mu \mathrm{g}$ HUT 102B2 mRNA, a cDNA library was constructed in $\lambda$ gt 10 according to the method of St. John, except that sizefractionated double-stranded cDNA was purified by absorption to glass silica mesh. The resultant cDNA library contained $2.4 \times 10^{6}$ recombinant phage clones with inserts ranging in size from 500 base pairs to several kilobases. Following amplification, 200000 phage clones were screened by Benton-Davis plaque hybridization [14] with a 17 nucleotide synthetic probe based on the protein sequence of the receptor (see Sect. C). Candidate clones were evaluated by selective hybridization of mRNA [15] and complete sequencing using the dideoxy chain termination method of Sanger and Coulson in M13 bacteriophage [16]. DNA sequence data were analyzed and compared on an IBM system 370 using the program described by Queen and Korn. cDNA were expressed by ligating each into the EcoR1 site of pcEXV-1 (generously provided by Dr. James Miller and Dr. Ron Germain, NIH). This vector places the cDNA inserts under the control of the early SV40 promoter and enhancer sequences. These constructs were subsequently transfected into COS- 1 cells by calcium phosphate precipitation and evaluated for IL-2 receptor expression $48-72 \mathrm{~h}$ later in binding assays with purified radiolabeled IL-2 and antiTac. Analysis of genomic DNA and mRNA in varying cell lines was performed as previously described $[17,18]$.

\section{Results and Discussion}

\section{Purification of the Human IL-2 Receptor}

The IL-2 receptor was purified from NP-40 detergent extracts of HUT $102 \mathrm{~B} 2$ cells by immunoaffinity chromatography with antiTac antibody. The extract was first passed over a control UPC 10 monoclonal antibody column and then over the anti-Tac column. Following serial washes at varying ionic strengths, the receptor was eluted with $2.5 \%$ acetic acid. Following lyophilization, the receptor was found to retain biologic activity (capacity to bind IL-2) and was $>95 \%$ pure as judged by silver staining of SDS-polyacrylamide gels. The sequence of the $\mathrm{NH}_{2}$ terminal 29 amino acids was determined by gas phase microsequencing (100-250 pmol per analysis) and selected positions identified or confirmed by sequencing receptor biosynthetically labeled with radioactive amino acids (Table 1).

\section{Molecular Cloning of cDNA Cor- responding to the Human IL-2 Receptor}

Based on the protein sequence, an oligonucleotide probe 17 nucleotides in length with 64-fold degeneracy was synthesized (Table 2). This oligonucleotide probe was used to screen 200000 recombinant phages from the amplified HUT 102B2 cDNA library. Following sequential screening, 11 candidate phage clones containing cDNA inserts which hybridized to the $17 \mathrm{mer}$ were identified (Fig. 1). Clone 2 (900 base pairs), clone 3 (2400 base pairs), and clone 4 (1600 base pairs) were chosen for further analysis and subcloned into pBR322. Each of these clones was evaluated for the capacity to hybridize selectively to mRNA which, when translated and immunoprecipitated, would produce the primary translation product of the IL-2 receptor. As shown in Fig. 2, each of the three clones, but not pBR327 nor filters without DNA, selectively hybridized to IL-2 receptor mRNA. These data suggested the association of these cDNA with the human IL-2 receptor.

Each of the inserts or appropriate restriction fragments from clones 2,3 , and 4 were subcloned into M13 bacteriophage and the complete DNA sequence determined. A complete listing of these sequences is reported in reference [19]. Each of the sequences contained a long open reading frame, including a region of 87 nucleotides which coded for the $29 \mathrm{NH}_{2}$ terminal amino acids determined by protein sequencing; thus, their relationship to the IL-2 receptor was confirmed. However, comparison of the sequences of clone 3 and 4 revealed that clone 4 lacked a 216 base pairs segment within the protein coding region which was present in clone 3 . Further, 
this segment was flanked on either side by the sequence TTCCAGGT, indicative of a typical mRNA donor and acceptor splicing site [20]. Thus, the presence of this internally truncated cDNA suggested that an alternate pathway of mRNA processing existed for the IL-2 receptor. Since the predicted protein from the spliced cDNA (clone 4) was 72 amino acids shorter than that encoded by the unspliced cDNA (clone 3), but otherwise identical, it was unclear which cDNA corresponded to the true IL-2 receptor mRNA. To address this issue, the cDNA inserts from clone 3 and 4 were ligated into an expression vector pcEXV-1 which contains SV40 promoter and enhancer sequences. Plasmids with the cDNA in the correct orientation were then transfected into COS-1 cells by calcium phosphate precipitation and analyzed for directed synthesis of the IL-2 receptor. As shown in Fig. 3, radiolabeled binding of IL-2 and anti-Tac occurred only when the unspliced cDNA was transfected (clone 3). Further, cell surface iodination and immunoprecipitation with anti-Tac confirmed the presence
Fig. 1. DNA from 12 recombinant $\lambda$ gt10 phage clones selected in serial screening with the $17 \mathrm{mer}$ were restricted with EcoR1, electrophoresed on a $1 \%$ agarose gel, transferred to nitrocellulose, and probed with the $17 \mathrm{mer}$. Inserts from 11 of the 12 phage clones hybridized to the $17 \mathrm{mer}$, however, two negative phage clones (N28, N29) which contained 1 kilobase inserts did not hybridize. Phage clones 2, 3, and 4 were chosen for further analysis as they were representative of the smallest and two largest cDNA insert

of the $M_{\mathrm{r}}=50000$ receptor characteristic of HUT 102B2 cells. In contrast, the spliced cDNA, while effectively transcribed, did not result in the production of receptors capable of binding either IL-2 or anti-Tac. These data raise the possibility that IL-2 receptor expression may not only be regulated at the level of initiation of transcription, but also at a posttranscriptional step involving splicing of this internal segment.

Table 1. NH, terminal amino acid sequence of the human IL-2 receptor ${ }^{\mathrm{a}}$

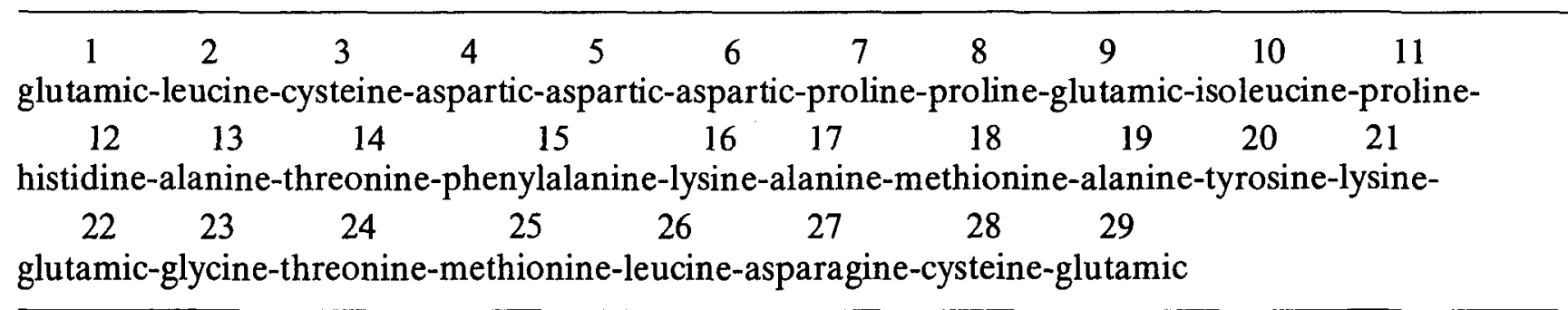

a The human IL-2 receptor from HUT 102B2 was sequenced by automated Edman degradation on a gas phase sequencer followed by analysis of samples by high liquid chromatography. The positions of leucine, cysteine, aspartic acid, proline, and methionine were determined or confirmed by sequencing of receptor biosynthetically labeled with the respective radioactive amino acid

Table 2. Nucleotide sequence of the synthetic oligonucleotide probes complementary to mRNA corresponding to amino acids $3-8^{a}$

$$
\begin{aligned}
& \text { G-G-A/G-G-G-A/G-T-C-A/G-T-C-A/G-T-C-A/G-C-A } \\
& \text { G-G-C/T-G-G-A/G-T-C-A/G-T-C-A/G-T-C-A/G-C-A }
\end{aligned}
$$

a Since the 17 nucleotide sequence for amino acids 3-8 was 64-fold degenerate, the oligonucleotides were synthesized in two separate pools each containing 32 species. Following end-labeling with ATP ${ }^{32} \mathrm{P}$ and polynucleotide kinase, both pools identified two mRNA in Northern blotting experiments and thus Benton-Davis screening of the cDNA library was performed with a mixture of both pools 
$\begin{array}{llllllllllllll}1 & 2 & 3 & 4 & 9 & 13 & 14 & 20 & 21 & 23 & 28 & 30 & 27 & 29\end{array}$
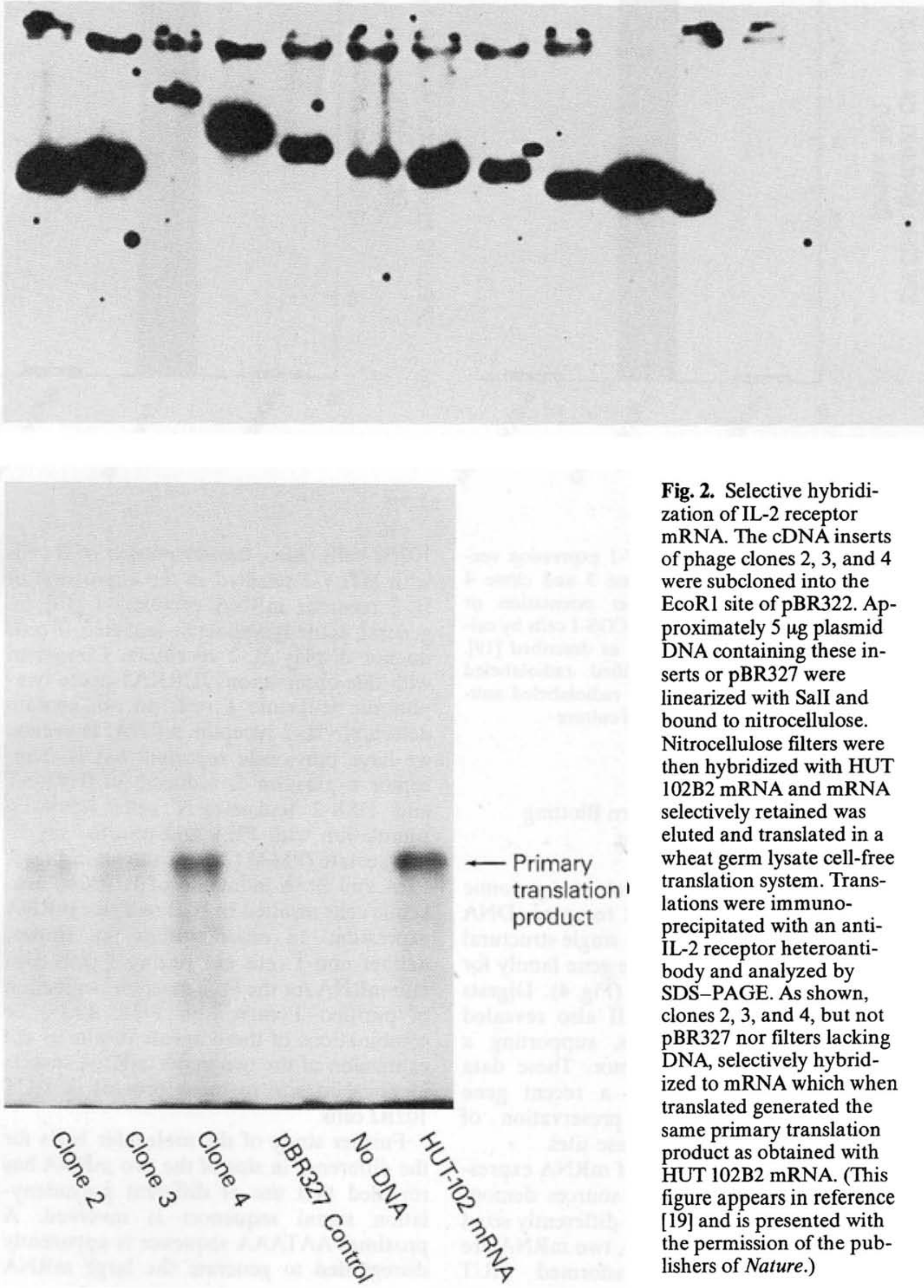

Fig. 2. Selective hybridization of IL-2 receptor mRNA. The cDNA inserts of phage clones 2,3 , and 4 were subcloned into the EcoR1 site of pBR322. Approximately $5 \mu \mathrm{g}$ plasmid DNA containing these inserts or pBR327 were linearized with SalI and bound to nitrocellulose. Nitrocellulose filters were then hybridized with HUT 102B2 mRNA and mRNA selectively retained was eluted and translated in a wheat germ lysate cell-free translation system. Translations were immunoprecipitated with an antiIL-2 receptor heteroantibody and analyzed by SDS-PAGE. As shown, clones 2, 3, and 4, but not pBR327 nor filters lacking DNA, selectively hybridized to mRNA which when translated generated the same primary translation product as obtained with HUT 102B2 mRNA. (This figure appears in reference [19] and is presented with the permission of the publishers of Nature.) 


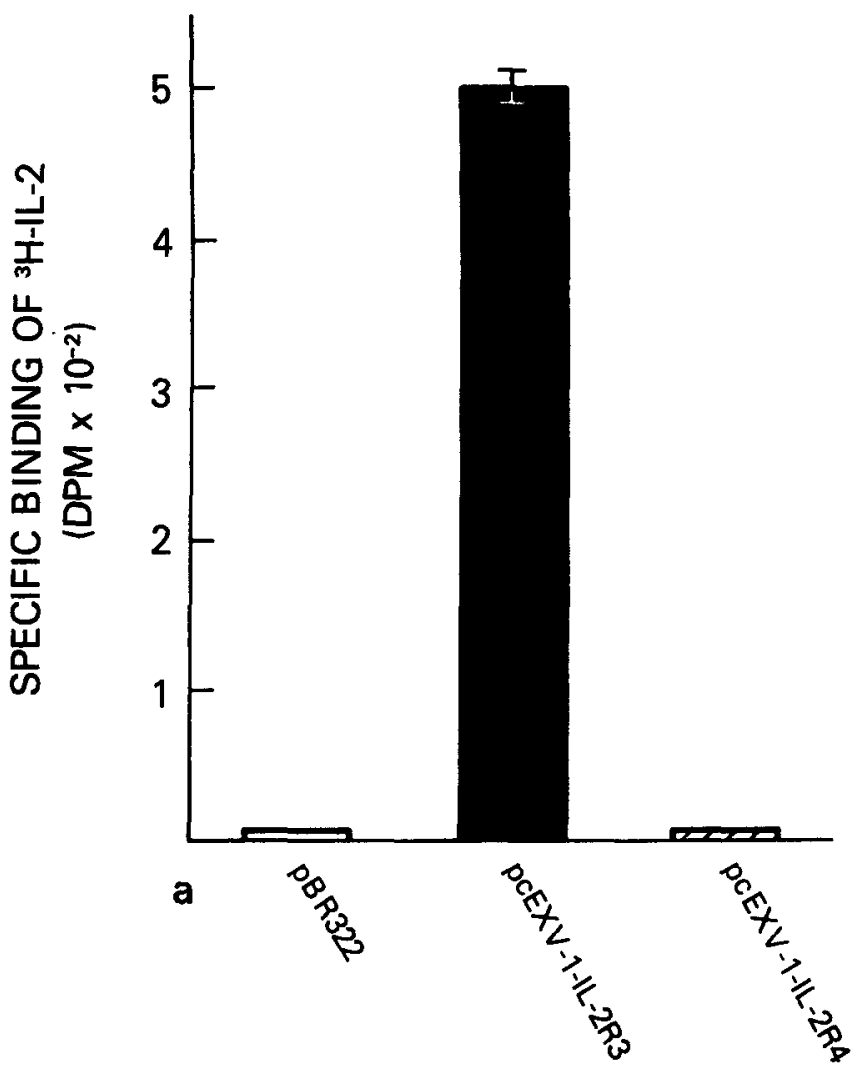

Fig. 3a, b. DNA from pcEXV-1 expression vector constructs containing clone 3 and clone 4 cDNA inserts in the proper orientation or pBR322 were transfected into COS- 1 cells by calcium phosphate precipitation as described [19]. Specific binding of a purified radiolabeled JURKAT IL-2 and b purified radiolabeled antiTac was measured after $48 \mathrm{~h}$ of culture

\section{Southern and Northern Blotting}

Studies of the IL-2 Receptor

Southern blots of EcoR1-restricted genomic DNA probed with an IL-2 receptor cDNA suggested the presence of a single structural gene rather than a multiple gene family for the human IL-2 receptor (Fig. 4). Digests with Bam $\mathrm{Hl}$ and HindIII also revealed simple patterns of bands, supporting a single gene for this receptor. These data however do not exclude a recent gene duplication event with preservation of these restriction endonuclease sites.

Northern blot analysis of mRNA expression from several cellular sources demonstrated the presence of two differently sized mRNA. As shown in Fig. 5, two mRNA are present in HTLV-1-transformed HUT

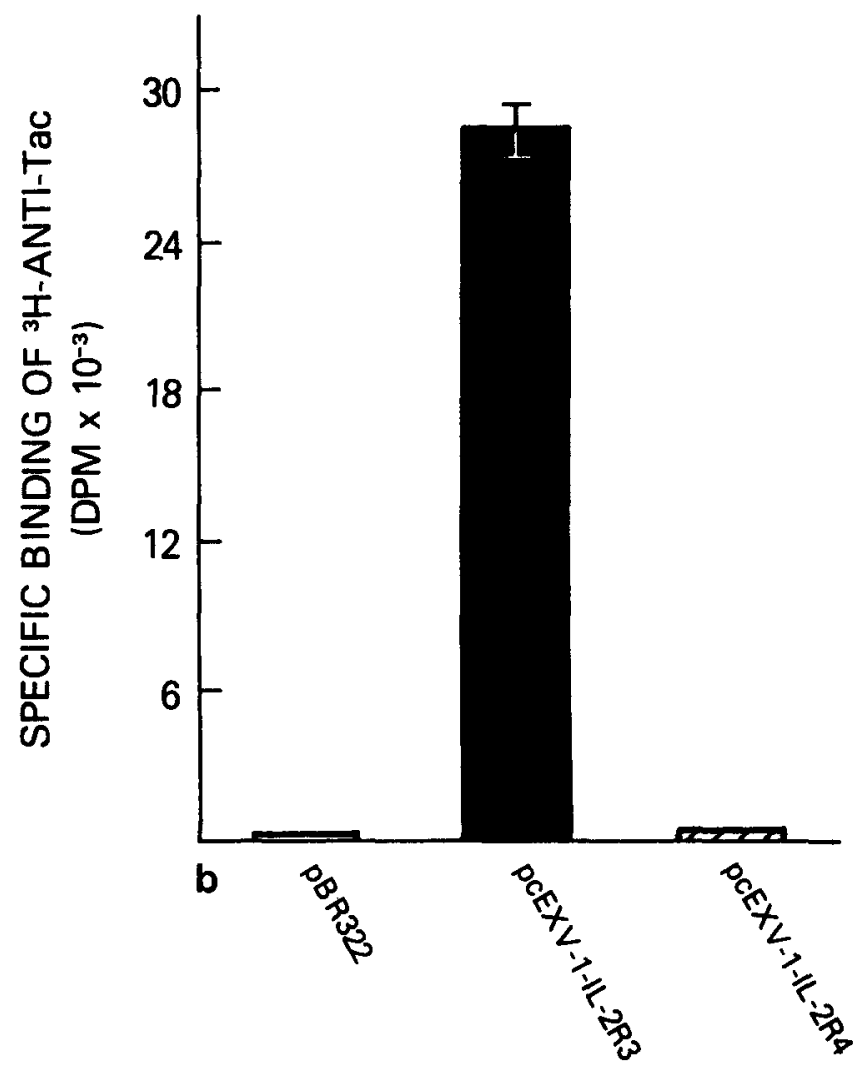

102B 2 cells. Also, transformation of B cells with HTLV-1 resulted in the expression of IL-2 receptor mRNA production [19]. In general, acute lymphocytic leukemic T cells do not display IL-2 receptors. Consistent with this observation, JURKAT acute lymphocytic leukemic $T$ cells do not contain detectable IL-2 receptor mRNA. However, we have previously reported that IL-2 receptor expression is induced in JURKAT and HSB-2 leukemic $T$ cells following stimulation with PHA and phorbal myristate acetate (PMA) [21]. As shown in Fig. 5, PHA and PMA induction of JURKAT leukemic cells resulted in IL-2 receptor mRNA expression. In other studies not shown, neither non- $T$ cells nor resting $T$ cells contain mRNA for the IL-2 receptor. Induction of purified $T$ cells with PHA, PMA, or combinations of these agents results in the expression of the two major mRNA species identical in size to those present in HUT 102B2 cells.

Further study of the molecular basis for the difference in size of the two mRNA has revealed that use of different polyadenylation signal sequences is involved. A proximal AATAAA sequence is apparently disregarded to generate the large mRNA 


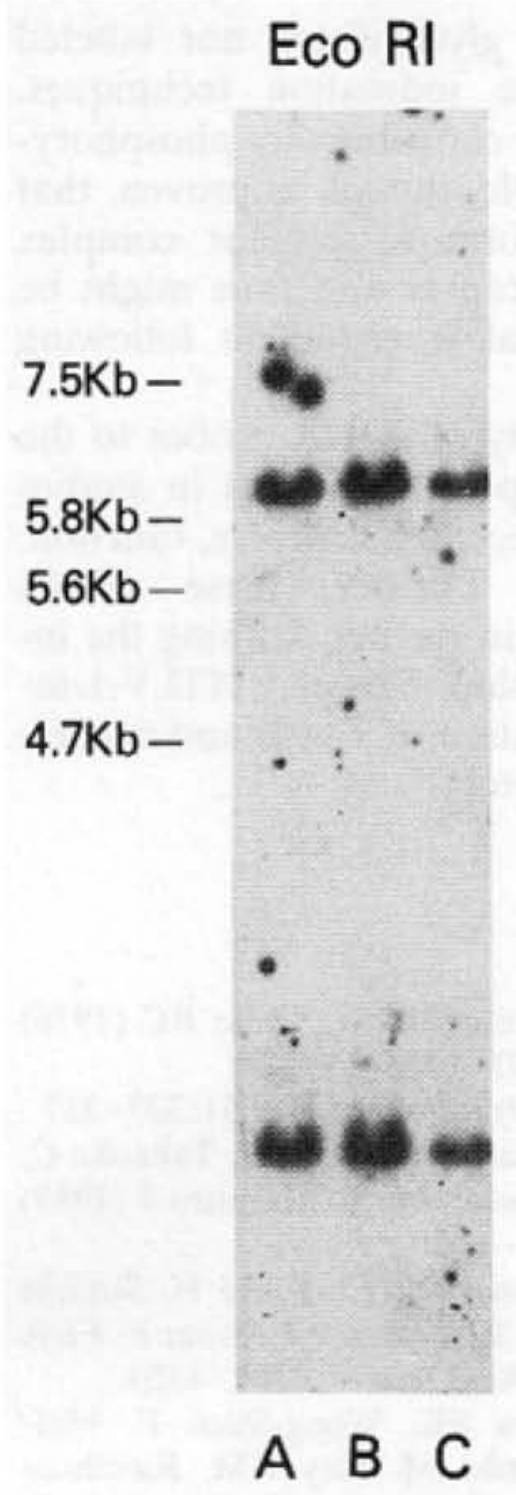

Fig. 4. Southern blot analysis of human genomic DNA restricted with EcoR1 probed with ${ }^{32} \mathrm{P}-$ labeled IL-2 receptor cDNA containing 937 bases from the $5^{\prime}$ end of the mRNA. DNA were isolated from human placenta (lane $A$ ) and human tonsil (lanes $B$ and $C$ ). More recent blots also indicate the presence of a 10 kilobases band in EcoRl digests seen faintly in the autoradiogram. (This figure appears in reference [19] and is presented with the permission of the publishers of Nature.)

(3500 nucleotides) while the smaller mRNA (1500 nucleotides) is produced when the proximal polyadenylation signal sequence is utilized [19]. Both mRNA appear functional since size separation of HUT 102B2 mRNA on a methylmercuric hydroxide gel, translation of mRNA from different slices of the gel, and immunoprecipitation of the resultant proteins demonstrate the primary translation product for the receptor from fractions corresponding to both the small and large mRNA.

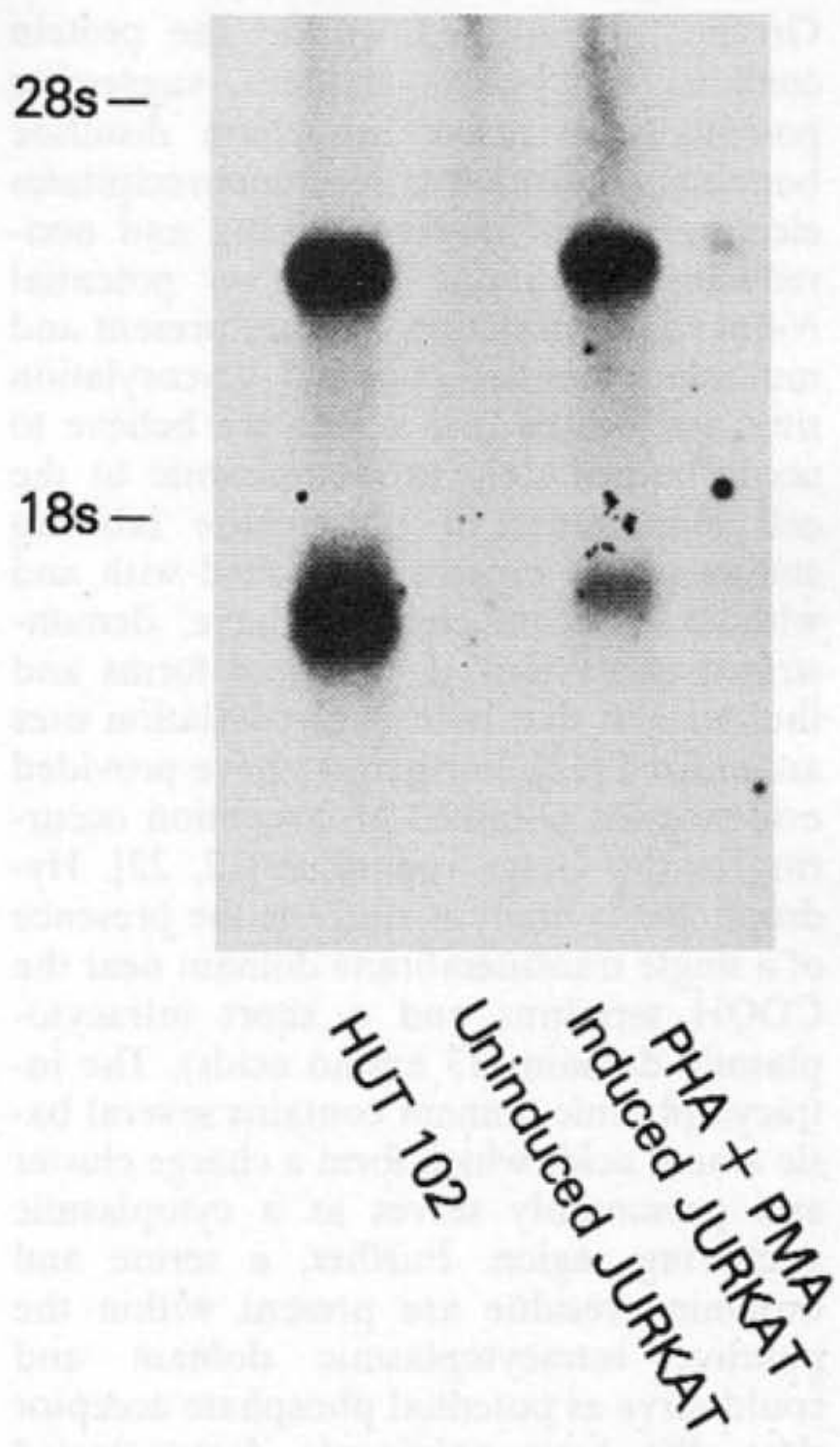

Fig. 5. Northern blot of IL-2 receptor mRNA expression in HUT 102B2 cells, JURKAT leukemic $\mathrm{T}$ cells, and JURKAT leukemic $\mathrm{T}$ cells induced for $18 \mathrm{~h}$ with PHA $(1 \mu \mathrm{g} / \mathrm{ml})$ and PMA $(50 \mathrm{ng} /$ $\mathrm{ml}) ; 10 \mu \mathrm{g}$ oligo(dT)-selected mRNA was electrophoresed in each lane and blots were brobed with nick-translated IL-2 receptor cDNA. Migration of $28 S$ and $18 S$ ribosomal RNA is indicated

\section{Analysis of the Primary Structure} of the Human IL-2 Receptor

The complete amino acid sequence of the IL-2 receptor was deduced from the cDNA sequence [19]. The receptor is composed of 272 amino acids, including a signal peptide of 21 amino acids. The length of the signal peptide has been confirmed preliminarily by sequencing the primary translation product after labeling with methionine ${ }^{35} \mathrm{~S}$ (W.J. Leonard, S. Rudikoff, and W.C. 
Greene, unpublished work). The protein contains 13 cysteine residues, suggesting potentially extensive intrachain disulfide bonding, confirmed in immunoprecipitates electrophoresed under reducing and nonreducing conditions [12]. Two potential $N$-linked glycosylation sites are present and multiple potential $O$-linked glycosylation sites are located in a region we believe to occur immediately extractoplasmic to the cell membrane. In pulse-chase labeling studies of the protein performed with and without tunicamycin, we have demonstrated two $N$-linked precursor forms and thus suggest that both $N$-glycosylation sites are utilized [12]. Further, we have provided evidence for $O$-linked glycosylation occurring in the Golgi apparatus [12, 22]. Hydrophobicity analysis suggests the presence of a single transmembrane domain near the $\mathrm{COOH}$ terminus and a short intracytoplasmic domain (13 amino acids). The intracytoplasmic domain contains several basic amino acids which form a charge cluster and presumably serves as a cytoplasmic anchoring region. Further, a serine and threonine residue are present within the putative intracytoplasmic domain and could serve as potential phosphate acceptor sites. We have previously demonstrated that this receptor is constitutively phosphorylated [22].

A second moderately hydrophobic region exists within the protein, but is removed in the spliced form of the receptor. It is unlikely that this region represents a second transmembrane crossing as this would result in the $N$-linked glycosylation sites occurring within the cytoplasm which would be without precedent. However, this region could represent a loop into the membrane. Alternatively, this segment may be involved in the binding of IL-2 which is unexpectedly rich in hydrophobic residues.

In view of the exceedingly short intracytoplasmic tail predicted by the DNA sequence, it seems unlikely that signal transduction by the receptor involves an enzymatic activity of this domain. In immunoprecipitates labeled with methionine ${ }^{35} \mathrm{~S}$, we have previously observed coprecipitation of two larger proteins $\left(M_{\mathrm{r}}=113000\right.$ and 180000$)$. These proteins appear to be located on the inner face of the membrane as they are not glycosylated nor labeled with cell surface iodination techniques. However, each is constitutively phosphorylated. It is possible, though unproven, that these proteins form a receptor complex with the IL-2 receptor and thus might be involved in signal transduction following IL-2 binding.

The availability of cDNA probes to the IL-2 receptor hopefully will aid in studies relating to IL-2 receptor structure, function, and regulation. Further, these cDNA should be useful in further defining the intriguing relationship between HTLV-1-induced transformation of $\mathrm{T}$ cells and expression of IL-2 receptors.

\section{References}

1. Morgan DA, Ruscetti FW, Gallo RC (1976) Science 193: 1007-1008

2. Smith KA (1980) Immunol Rev 51:337-357

3. Taniguchi T, Matsui H, Fujita T, Takaoka C, Kashima N, Yoshimoto R, Hamuro J (1983) Nature 302:305-310

4. Devos R, Paetinck G, Cheroute $H$, Simons G, Degrave W, Tavernier J, Remout E, Fiers W (1983) Nucl Acid Res 11:4307-4323

5. Clark SC, Arya SK, Wong-Staal F, Matsumoto-Kobayashi M, Kay RM, Kaufman RJ, Brown EL, Shoemaker C, Copeland T, Oroszlan S, Smith KA, Sarngadharan MG, Lindner SG, Gallo RC (1984) Proc Natl Acad Sci USA 81:2543-2547

6. Fujita T, Takeoka C, Matsui $\mathrm{H}$, Taniguchi T (1983) Proc Natl Acad Sci USA 81: 1634-1638

7. Robb RJ, Munck A, Smith KA (1981) J Exp Med 154: 1455-1474

8. Greene WC, Robb RJ (1984) In: Gillis S (ed) Contemporary topics in molecular immunology. Plenum, NY 10:1

9. Depper JM, Leonard WJ, Kronke M, Waldmann TA, Greene WC (1984) J Immunol 133: 1691-1695

10. Uchiyama $\mathrm{T}$, Broder $\mathrm{S}$, Waldmann $\mathrm{TA}$ (1981) J Immunol 126:1393-1397

11. Leonard WJ, Depper JM, Uchiyama T, Smith KA, Waldmann TA, Greene WC (1982) Nature 300:267-269

12. Leonard WJ, Depper JM, Robb RJ, Waldmann TA, Greene WC (1983) Proc Natl Acad Sci USA 80:6957-6961

13. Robb RJ, Greene WC (1983) J Exp Med 158: 1332-1337

14. Benton WD, Davis RW (1977) Science 196: 180-182 
15. Maniatis T, Fritsch EF, Sambrook J (1982) In: Molecular cloning. Cold Spring Harbor Laboratory, pp 330-333

16. Sanger F, Coulson AR (1975) J Mol Biol 94:414-418

17. Southern EM (1975) J Mol Biol 98:503-517

18. Thomas PS (1980) Proc Natl Acad Sci USA 77:5201-5205

19. Leonard WJ, Depper JM, Crabtree GR, Rudikoff S, Pumphrey J, Robb RJ, Kronke M, Svetlik PB, Peffer NJ, Waldmann TA, Greene WC (1984) Nature 311:626-631
20. Breathnach R, Benoist C, O'Hare K, Gannon F, Chambon P (1978) Proc Natl Acad Sci USA 75:4853-4857

21. Greene WC, Robb RJ, Depper JM, Leonard WJ, Drogula C, Svetlik PB, Wong-Staal F, Gallo RC, Waldmann TA, Greene WC (1984) J Immunol 133: 1042-1047

22. Leonard WJ, Depper JM, Robb RJ, Kronke M, Waldmann TA, Greene WC (1985) J Biol Chem 260: 1872-1880 